\title{
Maladaptive daydreaming as a new form of behavioral addiction
}

\author{
IGOR J. PIETKIEWICZ ${ }^{1 *}$, SZYMON NĘCKI ${ }^{2}$, ANNA BAŃBURA ${ }^{2}$ and RADOSŁAW TOMALSKI ${ }^{1}$ \\ ${ }^{1}$ Research Centre for Trauma \& Dissociation, Katowice Faculty of Psychology, SWPS University of \\ Social Sciences and Humanities, Katowice, Poland \\ ${ }^{2}$ Faculty of Psychology, Jagiellonian University, Kraków, Poland
}

(Received: February 16, 2018; revised manuscript received: May 27, 2018; second revised manuscript received: July 17, 2018; accepted: August 13, 2018)

\begin{abstract}
Background and aims: Maladaptive daydreaming (MD) has many features of behavioral addiction, but research exploring this syndrome is limited. This case study provides a qualitative exploration of MD. Methods: A structured clinical interview and mental state examination of a patient with MD were video-recorded and transcribed verbatim. Transcripts were subjected to the interpretative phenomenological analysis. Results: MD was developed as a strategy to cope with distress but led to uncontrollable absorption in fantasy, social withdrawal, and neglecting aspects of everyday life. It was coupled with excessive Internet use and viewing porn. Discussion and conclusions: Patients should be questioned about MD during clinical assessment. Further studies are necessary to determine whether MD constitutes a separate syndrome or is a part of other behavioral addictions.
\end{abstract}

Keywords: maladaptive daydreaming, absorption, social exclusion, bullying, addictive behavior

\section{INTRODUCTION}

While the fifth edition of Diagnostic and Statistical Manual of Mental Disorders (DSM-5) only lists the gambling disorder in the behavioral addictions chapter, authors also consider additional forms, such as Internet gaming disorder, and recommend further research into excessive use of social media or viewing pornography (American Psychiatric Association [APA], 2013). Internet gaming may involve role-playing games (RPGs) or live action RPG in which participants are identified with their characters and co-create imagined scenarios (Tychsen, Brolund, \& Kavakli, 2006; Vorobyeva, 2016). Some people use paid services allowing participants to create avatars and virtual environments in which they interact with others, for example, World of Warcraft or Second Life (Messinger, Stroulia, \& Lyons, 2008). Studies show that users often develop idealized versions of themselves, with personality traits or preferences similar to their own, and engage in normal actions, such as socializing or shopping or express forbidden, conflicting desires (Gottschalk, 2010; Linares, Subrahmanyam, Cheng, \& Guan, 2011). RPGs, which are in significant imaginative involvement, compared with other types (e.g., shooters or strategic games), have been associated with the highest risk of generating behavioral addiction (Lee et al., 2007; Lemmens \& Hendriks, 2016).

There is a growing body of evidence identifying dysfunctional forms of imaginative involvement, defined as maladaptive daydreaming (MD), which may be expressed through extensive book-reading, watching films, or gaming. MD refers to extensive, often compulsive, absorption in fantasy for several hours a day, which replaces human interaction and impairs functioning in various domains: academic, interpersonal, or vocational (Somer, 2002, 2018). This syndrome was found in patients with a wide range of DSM-5 disorders, including attention-deficit hyperactivity disorder, anxiety disorder, depressive disorder, and obsessive-compulsive or related disorders (Somer, Soffer-Dudek, \& Ross, 2017). Somer (2002) initially associated MD with dissociative pathology and personality disorders. More recently, however, he described this behavior in relation to four categories: a dissociative disorder, disturbance of attention, obsessive-compulsive spectrum disorder, or behavioral addiction (Somer, 2018). Maladaptive daydreamers may share certain similarities with problematic Internet gamers who play games to avoid real-life difficulties (escapism), and use fantasy to experience things that are not workable in real life or live out alternative identities through the game (Ballabio et al., 2017). Escapism, according to Demetrovics et al. (2011), should be distinguished from coping (i.e., improvement of mood or channeling of aggression), which has no clear relationship with problematic gaming. MD could be considered a behavioral addiction, because it is so rewarding that people experience intense yearning for it or feel compelled to extend and repeat this action (Somer, Somer, \& Jopp,

\footnotetext{
* Corresponding author: Igor J. Pietkiewicz; Research Centre for Trauma \& Dissociation, Katowice Faculty of Psychology, SWPS University of Social Sciences and Humanities, Techników 9, Katowice 40 326, Poland; Phone: +48 602648 713; E-mail: ipietkiewicz@swps.edu.pl
}

This is an open-access article distributed under the terms of the Creative Commons Attribution-NonCommercial 4.0 International License, which permits unrestricted use, distribution, and reproduction in any medium for non-commercial purposes, provided the original author and source are credited, a link to the CC License is provided, and changes - if any - are indicated. 
2016b). Some report an irresistible urge to immerse themselves in a fantasy world immediately on waking or want to continue fantasizing when interrupted (Bigelsen, Lehrfeld, Jopp, \& Somer, 2016). Bigelsen and Schupak (2011), however, note that daydreamers are also distressed about losing control over fantasizing and unsuccessful attempts to limit it.

There are only a few studies on MD, and its symptoms are often unacknowledged or dismissed during clinical assessment (Somer, Somer, \& Jopp, 2016a). Because this may lead to unsuccessful treatment, further research is required (Somer, 2018; Somer et al., 2016b). There is also an ongoing dispute among researchers whether or not to classify certain problematic behaviors as "new" behavioral addictions. To avoid overpathologizing the daily life activities, Billieux, Schimmenti, Khazaal, Maurage, and Heeren (2015) suggest that preliminary qualitative studies should precede quantitative research and explore underlying psychological processes and how certain behaviors are experienced, instead of merely comparing behavior against diagnostic criteria. This paper is in line with this approach. It presents a case study of a patient having MD with features of behavioral addiction, whose narrative was explored adhering to rigorous diagnostic and methodological procedures of the interpretative phenomenological analysis (IPA).

\section{METHODS}

This study took place in Poland in 2018 as part of the project exploring alterations in consciousness. IPA was used for data analysis. IPA generates rich and detailed descriptions of how individuals experience phenomena under investigation and synthesizes concepts derived from phenomenology, hermeneutics, and idiography. Detailed exploration of how participants make meaning of their world is combined with researchers' attempts to make sense of the participants' meaning (Pietkiewicz \& Smith, 2014).

\section{Participants}

Peter (his real name has been changed to ensure confidentiality), aged 25 years, is a single Caucasian male who has moved out of the family home and lives with a flatmate. He is about to complete an IT degree. He uses alcohol rarely and in small doses and has never used drugs or other psychoactive substances. He meets the DSM-5 criteria of the 301.82 avoidant personality disorder (he avoids interpersonal contacts fearing disapproval, criticism, and rejection; he has never had an intimate relationship or sexual initiation because of shame and fear; he is preoccupied about being socially ashamed or mocked and feels inadequate, inhibited, and socially inept; he has poor self-esteem and feels inferior; and he is reluctant to engage in activities potentially associated with being embarrassed). He also reported multiple symptoms indicating non-substance behavioral addiction associated with daydreaming and excessive Internet use for watching videos, pornography, playing games, and reading news. He has become increasingly involved in these activities to achieve desired excitement, experienced irritation when unable to continue that behavior, stayed preoccupied with it, and made repeated and unsuccessful attempts to control his mental and physical actions. He used that behavior to regulate affect but was ashamed and tried to conceal it, experiencing distress as a result. However, he reported neither posttraumatic stress disorder symptoms and somatoform or psychoform dissociation, nor symptoms indicating the existence of dissociative personality parts.

\section{Procedure}

The study was approved by the local university research committee. Our participant had been screened for dissociative experiences by a local psychiatrist who referred him to the Research Centre for Trauma \& Dissociation for an indepth diagnostic examination, where he was subjected to the Trauma and Dissociation Symptoms Interview - TADS-I (Boon \& Matthess, 2017) to explore his medical history, substance use, and various aspects of everyday functioning (including sleep, eating, self-image, mood regulation, interpersonal relationships, and alterations in consciousness). TADS-I is a comprehensive tool for a differential diagnosis of dissociative disorders, thoroughly examining alterations in consciousness (including depersonalization, derealization, absorption, and daydreaming) and symptoms indicating structural dissociation of the personality. The interview was held in two sessions and lasted approximately $4 \mathrm{hr}$ in total. A psychiatrist also performed a standard mental health assessment and informed the participant about his results and recommended treatment. All interviews were video recorded.

\section{Data analysis}

A detailed, verbatim transcript of the video recording was separately analyzed by all authors in Nvivo11 (computerassisted qualitative data analysis software), using the consecutive analytical steps recommended for IPA (Pietkiewicz \& Smith, 2014). First, the transcript was carefully read several times and researchers made their interpretative comments about the content and language use. They registered repetitive phrases, similes, and similarities in how the participant described various experiences at different points of the interview. The "hermeneutic circle" was applied in the analysis, meaning researchers tried to understand each individual part by reference to the whole and vice versa. Then, they categorized the notes into emergent themes by allocating descriptive labels (nodes) and discussed their coding and interpretations of data with each other. They analyzed the connections between themes and grouped themes according to conceptual similarities into superordinate ones and subthemes. This article presents an elaboration of salient themes relating to the experience of excessive daydreaming and the participant's associations and interpretations.

\section{Ethics}

The study procedures were carried out in accordance with the Declaration of Helsinki. The institutional review board of the SWPS University of Social Sciences \& Humanities 
approved the study. The participant was informed about the study and provided informed consent.

\section{RESULTS}

\section{Theme 1: Facing social rejection was unbearable}

In primary school first grade, Peter saw himself as a sociable and communicative and focused on school achievements. He had limited awareness of his competitive tendencies.

I think I didn't realise that I pushed too hard and they [classmates] didn't like it. I wasn't arrogant, selfish or unfriendly, I simply bragged about how fortunate I was. I craved the spotlight.

He could not understand why, months later, his classmates began to tease him, intimidate him in front of others, or inflict pain.

They mocked me all the time, and avoided me. I sat alone at the back in class and had no one to talk to. Everyone knew I was a figure of fun.

This led him to feel weak, inferior, and socially excluded. He felt especially ashamed and humiliated when teased or mocked in the presence of girls he found attractive.

\section{Theme 2: Seeking distraction and release of tension}

Perceiving himself as an outcast and feeling worthless, Peter sought ways to distract himself from negative thoughts. He played video games or browsed the Internet for many hours and masturbated excessively. This way of discharging emotional tension started at a young age and he calls it "my detox after school." Over the years, the time spent fantasizing increased, usually triggered by pictures, films, or news on the Internet, which he found difficult to stop.

I spend about 14 hours a day surfing on my computer, watching pictures of cars, YouTube, and wanking. Political news, for example, may trigger delusional fantasies in which I am a multimillionaire who would never let that situation happen. If nothing stops my fantasizing like going swimming or to the library - then I crave music, which gets me even more hopped up. I walk around the flat, imagining how it would be in that world. When I have had too much, I need to watch some porn and masturbate.

Peter thinks he initially tried to avoid painful reality by developing alternative scenarios of events and experiencing them as if they were real. In this way, he could regulate his emotions and cope with loneliness.

When I felt this pain as a child, I started imagining how things could be different. I created stories which never happened. To suppress that pain I would hug my pillow or quilt, thinking I was being comforted by someone else.

\section{Theme 3: Intense imaginative involvement}

In his experience, spending most of the time playing video games, browsing the Internet, and masturbating compulsively also involves excessive daydreaming, which gives him excitement and pleasure. Peter seeks solitude and favorable conditions to immerse himself in his fantasy world. He realizes that daydreaming increasingly consumed more time and energy. Over the years, he recorded this activity in his diary, growing concerned, and angry with himself when he realized that he had limited control over his compulsive behavior.

Time goes by and I am not really able to control it. I sit at my PC and daydream day by day. I start in the morning and realise it is already night. It started by the second grade but did not bother me then so much. Now I fear that I have wasted my life and opportunities.

Although daydreaming is pleasurable, he says he has developed a "delusional personality" and lost control over fantasizing, becoming afraid of losing touch with reality or that the "alter" will take over.

Triggers for excessive daydreaming. Peter blames the peers who bullied him at school for his current difficulties and coping strategies. He thinks he was overly stressed and lacked emotional support, which discouraged him from interaction with others and expressing his needs.

My main problem is that I was too traumatised to express my feelings and needs. No life, women, hobbies throughout these years ... only fear and shame about saying what I wanted. This is what they did to me at school.

Occasionally, Peter tries to concentrate on the "here and now" as his form of rehab. However, listening to music or watching media triggers or supports fantasies. It is easy for him to get "hooked" on one thought, which leads to him developing elaborate and exciting stories.

Thinking about something, I automatically create a scenario. For instance, I become this multimillionaire, giving an interview. People admire my wisdom, respect me and make way for me. I move around my flat, listening to music and getting really high. I live these delusions for a few hours, daydreaming about that life: driving cars, car racing, sex.

Experimenting with alters. The protagonists in his fantasy world are always men with special attributes associated with admiration or awe. They use their abilities to help others, which make Peter feel strong, proud, and special, because he imagines being them.

I created this delusional personality of a multimillionaire by building digital systems that allow mankind to conquer death and cure all mental or physical problems. Sometimes I am the king of Poland, a guardian of values, ideals, social order, or a hero who can do things that other people are unable to do. I rescue them. I am an FBI agent with a photographic memory, an Iron Man who kills Muslim terrorists, or I destroy villains like a Robocop. I am the best. 
He also produces elaborate fantasies in which he hugs women or aggressively penetrates them, which he attributes to his lack of intimate contacts. Peter maintains that being a virgin is another reason for his shame. In his imagination, he then inspires people who feel weak, hopeless, or possess other qualities he himself despises. In his daydreams, he ascribes vulnerability to those he would save. He also has a sense of moral triumph for not expressing openly hostile feelings toward those who caused him pain.

As a multimillionaire I visit my old school and share my story with the pupils. I tell them how I managed to conquer my own weakness and that this was the best lesson I received from life... not giving in to my hatred.

Fantasies are private experiences. Peter is ashamed of the fragile self-esteem and sensitivity to criticism or rejection that he first experienced at school. He sees expressing emotions and reacting to being teased as weakness, so feigns indifference. He says,

I don't want people to see my emotions, whether I am angry, happy, or sad. I want them to see nothing but my unimpressed attitude, my poker face.

Talking about his fantasy world evokes tension and extreme shame; thus, he has never spoken about daydreaming to any healthcare provider before and neither has anyone asked about absorption in earlier interviews.

\section{Theme 4: Regret for lost opportunities}

Although intense daydreaming helps Peter escape from painful reality and regulate his emotions, he is aware of the losses it involves. He believes that avoiding social interaction has deprived him of opportunities for experiences typical of his age. He especially regrets not having established an intimate relationship and a sense of maturity.

I love my addiction and know I can escape unpleasant situations with porn and daydreaming. But when I do that, I miss something more valuable - the chance to attract the love of a woman. I had no social life at school, missed parties and other chances to get to know girls. Later on, my peers would wake up in bed with women, have relationships, work and reach maturity. I never grew up. I could have learnt the taste of love, kisses, walks, hugging, sex.

\section{DISCUSSION}

Literature acknowledges that many people engage in daydreaming as a strategy to cope with distress (Winnicott, 1971). This may become maladaptive when used excessively, causing social withdrawal (Somer, 2002). MD has been considered in terms of four psychopathological categories: as a symptom of dissociation, disturbance of attention, obsessive-compulsive, or behavioral addiction (Somer, 2018). This case study illustrates the last category.
Several distinct components of behavioral addiction are commonly identified as: (a) salience - the activity becomes more important than anything else and dominates thinking, (b) mood modification - experiencing the activity leads to an arousing "buzz" or a "high," (c) tolerance ability to do increasing amounts of the particular activity, (d) withdrawal - unpleasant states when activity is discontinued or suddenly reduced, (e) conflict (inter- or intrapersonal), and (f) relapse - addictive patterns are easily and quickly restored even after a long time of abstinence or control (Griffiths, 2005). Although the DSM-5 only describes symptoms of gambling disorder, the Appendix lists additional forms of behavioral addiction that should be explored (e.g., excessive use of social media or watching porn), and proposes criteria for Internet gaming disorders (APA, 2013). Various authors note that this form of entertainment can lead to preoccupation (obsessive thinking about online games), overuse, neglecting areas of everyday life, social isolation, inter- and intrapersonal conflicts, and escape from painful reality (Demetrovics et al., 2012; King, Herd, \& Delfabbro, 2017, 2018; Király et al., 2017; Kuss, 2013; Kuss \& Griffiths, 2012). Such people risk substituting real life with virtual reality (Smahel, Blinka, \& Ledabyl, 2008).

While our subject has all these characteristics in relation to Internet use and viewing porn, he also reports MD as his main area of concern and difficulty. His MD alone involves seeking opportunities to indulge himself in fantasies and elaborate his scenarios (preoccupation), feeling very excited (mood modification), excessive and increasing use (tolerance), feeling irritated when something or someone disturbs his daydreaming (withdrawal), and inner frustration associated with avoiding confrontation with problems (conflict). Fantasy, which is normally a natural coping strategy to regulate affect, apparently becomes dysfunctional in MD and leads to escapism, causing impairment of functioning in school, work, and social life.

Our subject initially used daydreaming to distract his attention from problems at school or aid emotional regulation. Only later he discovered that daydreaming can be triggered using the Internet or viewing porn. Although he identified MD as his main problem for which he sought help, there were few days when fantasy dominated his functioning but did not involve using the Internet. This shows that further quantitative studies are necessary to distinguish whether MD is merely a component of other disorders or compulsive behaviors (e.g., personality disorder or porn/Internet addiction) or is an isolated symptom that justifies creating its own separate diagnostic category. Interestingly, our entire subject's compulsive behaviors (excessive Internet use, watching porn, and MD) required being absorbed. This justifies further studies into alterations in consciousness in people with behavioral addictions. It could be rewarding to analyze the function of imaginative involvement and its impact on daily life in people excessively using RPG (Tychsen et al., 2006; Vorobyeva, 2016) or virtual reality (Messinger et al., 2008).

Literature shows that adverse childhood experiences can lead to the structural dissociation of the personality (Nijenhuis, 2015; van der Hart, Nijenhuis, \& Steele, 2006). 
Our subject felt neglected at home and bullied at school, which resulted in alterations in consciousness (immersion in his inner world) and compulsive behavior. He also developed symptoms of avoidant personality and revealed narcissistic conflicts associated with shame and fragile selfesteem. However, he reported no symptoms of pathological dissociation. This supports the observation that some cases of MD do not involve dissociative pathology at all. Although MD may involve a disordered form of absorption, many researchers disregard these alterations in consciousness as dissociative in nature. This, however, relates to the ongoing theoretical dispute, what is dissociation per se, and will not be explained here.

Finally, it is interesting that our subject had never revealed his MD symptoms to any healthcare professional. This can be attributed to intense shame associated with the contents of his fantasies, limited control over imaginative involvement, and perceived consequences. This, however, justifies the need to openly ask questions about potential signs of MD during clinical interviews.

Funding sources: This publication has been created as part of the project funded by the National Science Centre, Poland, number: 2016/22/E/HS6/00306.

Authors' contribution: All authors made substantial contribution to acquisition, analysis, or interpretation of data.

Conflict of interest: The authors declare no conflict of interest.

\section{REFERENCES}

American Psychiatric Association [APA]. (2013). Diagnostic and statistical manual of mental disorders (DSM-5) (5th ed.). Arlington, VA: American Psychiatric Association.

Ballabio, M., Griffiths, M. D., Urbán, R., Quartiroli, A., Demetrovics, Z., \& Király, O. (2017). Do gaming motives mediate between psychiatric symptoms and problematic gaming? An empirical survey study. Addiction Research \& Theory, 25(5), 397-408. doi:10.1080/16066359.2017.1305360

Bigelsen, J., Lehrfeld, J. M., Jopp, D. S., \& Somer, E. (2016). Maladaptive daydreaming: Evidence for an under-researched mental health disorder. Consciousness and Cognition, 42, 254-266. doi:10.1016/j.concog.2016.03.017

Bigelsen, J., \& Schupak, C. (2011). Compulsive fantasy: Proposed evidence of an under-reported syndrome through a systematic study of 90 self-identified non-normative fantasizers. Consciousness and Cognition, 20(4), 1634-1648. doi:10.1016/j. concog.2011.08.013

Billieux, J., Schimmenti, A., Khazaal, Y., Maurage, P., \& Heeren, A. (2015). Are we overpathologizing everyday life? A tenable blueprint for behavioral addiction research. Journal of Behavioral Addictions, 4(3), 119-123. doi:10.1556/2006.4.2015.009

Boon, S., \& Matthess, H. (2017). Trauma and Dissociation Symptoms Interview (TADS-I), version 1.9. Unpublished manuscript.
Demetrovics, Z., Urbán, R., Nagygyörgy, K., Farkas, J., Griffiths, M. D., Pápay, O., Kökönyei, G., Felvinczi, K., \& Oláh, A. (2012). The development of the Problematic Online Gaming Questionnaire (POGQ). PLoS One, 7(5), e36417. doi:10.1371/ journal.pone. 0036417

Demetrovics, Z., Urbán, R., Nagygyörgy, K., Farkas, J., Zilahy, D., Mervó, B., Reindl, A., Ágoston, C., Kertész, A., \& Harmath, E. (2011). Why do you play? The development of the Motives for Online Gaming Questionnaire (MOGQ). Behavior Research Methods, 43(3), 814-825. doi:10.3758/s13428-011-0091-y

Gottschalk, S. (2010). The presentation of avatars in second life: Self and interaction in social virtual spaces. Symbolic Interaction, 33(4), 501-525. doi:10.1525/si.2010.33.4.501

Griffiths, M. (2005). A 'components' model of addiction within a biopsychosocial framework. Journal of Substance Use, 10(4), 191-197. doi:10.1080/14659890500114359

King, D. L., Herd, M. C., \& Delfabbro, P. H. (2017). Tolerance in Internet gaming disorder: A need for increasing gaming time or something else? Journal of Behavioral Addictions, 6(4), 525-533. doi:10.1556/2006.6.2017.072

King, D. L., Herd, M. C., \& Delfabbro, P. H. (2018). Motivational components of tolerance in Internet gaming disorder. Computers in Human Behavior, 78, 133-141. doi:10.1016/j. chb.2017.09.023

Király, O., Sleczka, P., Pontes, H. M., Urbán, R., Griffiths, M. D., \& Demetrovics, Z. (2017). Validation of the ten-item Internet Gaming Disorder Test (IGDT-10) and evaluation of the nine DSM-5 Internet Gaming Disorder criteria. Addictive Behaviors, 64, 253-260. doi:10.1016/j.addbeh.2015.11.005

Kuss, D. J. (2013). Internet gaming addiction: Current perspectives. Psychology Research and Behavior Management, 6, 125-137. doi:10.2147/PRBM.S39476

Kuss, D. J., \& Griffiths, M. D. (2012). Internet gaming addiction: A systematic review of empirical research. International Journal of Mental Health and Addiction, 10(2), 278-296. doi:10.1007/s11469-011-9318-5

Lee, M. S., Ko, Y. H., Song, H. S., Kwon, K. H., Lee, H. S., Nam, M., \& Jung, I. K. (2007). Characteristics of Internet use in relation to game genre in Korean adolescents. CyberPsychology \& Behavior, 10(2), 278-285. doi:10.1089/cpb.2006.9958

Lemmens, J. S., \& Hendriks, S. J. F. (2016). Addictive online games: Examining the relationship between game genres and Internet gaming disorder. Cyberpsychology, Behavior, and Social Networking, 19(4), 270-276. doi:10.1089/cyber.2015.0415

Linares, K., Subrahmanyam, K., Cheng, R., \& Guan, S. S. A. (2011). A second life within second life: Are virtual world users creating new selves and new lives? International Journal of Cyber Behavior, Psychology and Learning (IJCBPL), 1(3), 50-71. doi:10.4018/ijcbpl.2011070104

Messinger, P. R., Stroulia, E., \& Lyons, K. (2008). A typology of virtual worlds: Historical overview and future directions. Journal for Virtual Worlds Research, 1(1), 1-18. doi:10.4101/jvwr. v1i1.291

Nijenhuis, E. (2015). The trinity of trauma: Ignorance, fragility, and control. Bristol, CT: Vandenhoeck \& Ruprecht.

Pietkiewicz, I. J., \& Smith, J. A. (2014). A practical guide to using interpretative phenomenological analysis in qualitative research psychology. Psychological Journal, 20(1), 7-14. doi:10.14691/CPPJ.20.1.7

Smahel, D., Blinka, L., \& Ledabyl, O. (2008). Playing MMORPGs: Connections between addiction and identifying 
with a character. CyberPsychology \& Behavior, 11(6), 715-718. doi: $10.1089 / \mathrm{cpb} .2007 .0210$

Somer, E. (2002). Maladaptive daydreaming: A qualitative inquiry. Journal of Contemporary Psychotherapy, 32(2-3), 197-212. doi:10.1023/A:1020597026919

Somer, E. (2018). Maladaptive daydreaming: Ontological analysis, treatment rationale; a pilot case report. Frontiers in the Psychotherapy of Trauma and Dissociation, 1(2), 1-22. doi:10.XXXX/ftpd.2017.0006

Somer, E., Soffer-Dudek, N., \& Ross, C. A. (2017). The comorbidity of daydreaming disorder (maladaptive daydreaming). The Journal of Nervous and Mental Disease, 205(7), 525-530. doi:10.1097/NMD.0000000000000685

Somer, E., Somer, L., \& Jopp, D. S. (2016a). Childhood antecedents and maintaining factors in maladaptive daydreaming. The Journal of Nervous and Mental Disease, 204(6), 471-478. doi:10.1097/NMD.0000000000000507
Somer, E., Somer, L., \& Jopp, D. S. (2016b). Parallel lives: A phenomenological study of the lived experience of maladaptive daydreaming. Journal of Trauma \& Dissociation, 17(5), 561-576. doi:10.1080/15299732.2016.1160463

Tychsen, A., Brolund, T., \& Kavakli, M. (2006). Live action roleplaying games, control, communication, storytelling, and MMORPG similarities. Games and Culture, 1(3), 252-275. doi:10.1177/1555412006290445

van der Hart, O., Nijenhuis, E., \& Steele, K. (2006). The haunted self: Structural dissociation and the treatment of chronic traumatization. New York, NY/London, UK: W.W. Norton \& Co.

Vorobyeva, O. G. V. (2016). Constructing of group identity during live-action role-playing games. Russian Social Science Review, 57(3), 181-193. doi:10.1080/10611428. 2016.1195224

Winnicott, D. W. (1971). Playing and reality. New York, NY: Routledge. 